\title{
Please Mind the Stress: The Influence of Technostress on Mindset-Driven Sustainable Consumption in an Online Shopping Context
}

\author{
Katharina Schumacher \\ katharinaschumacher@hotmail.de
}

\author{
Leonore Peters \\ University of Bamberg \\ leonore.peters@uni-bamberg.de
}

\author{
Jasmin Feste \\ University of Bamberg \\ jasmin.feste@,uni-bamberg.de
}

\begin{abstract}
Though reportedly aware, the importance of sustainability is not reflected in consumers' consumption behavior. Existing research excludes both the concept of mindset as a driver for sustainable consumption and the diminishing effect of stress on this relationship. We close this gap by examining how a growth mindset indirectly affects consumers' sustainable purchase decisions, mediated by the preference for sustainable products, and the influence of technostress in an experimental online shopping scenario. Results based on 121 participants show a positive indirect effect of growth mindset on consumers' sustainable product choice, mediated by their general preference for sustainable products, while technostress has a negative moderating effect on the relationship between preference for and choice of sustainable products. Our study contributes to the ecommerce and consumer psychology literature and extends research by showing how external influences disrupt the purchase decision of consumers who are usually inclined towards purchasing sustainable products under non-invasive conditions.
\end{abstract}

\section{Introduction}

With climate change being one of the biggest challenges of our time, it is not surprising that the sustainable market opportunities for the private sector are projected to be worth up to US\$12 trillion a year by 2030 [1]. According to McKinsey \& Company, sustainability topped the list of biggest opportunities for the fashion industry for the first time in 2020, reflecting the consumers' increased awareness of the importance of sustainable clothing [2], though this awareness does reportedly not equally manifest in actual sustainable purchase behavior [3].

Research to date has revealed a number of factors influencing sustainable consumer intentions and behaviors $[4,5,6,7,8,9,10]$ and has also shown that our mindset, i.e., the way we perceive ourselves, others and the world around us together with the attached beliefs on whether we are able to change those conditions or not, is associated with general iproenvironmental behavioral inclination and action [11, 12]. However, the concept of mindset has not yet been considered to influence our inclination towards specifically pro-sustainable products and actual sustainable product choice.

While the consumers' consciousness for sustainability increased over the past years, ecommerce is also accelerating on a global scale and got its ultimate push during the global Covid-19 pandemic, with online purchases increasing $6-10 \%$ across most product categories [13]. Features such as $24 / 7$ opening hours, access to almost all product categories or the opportunity to compare between several offers certainly contribute to making online shopping an attractive alternative to stationary retail.

However, the online shopping experience can be diminished by the occurrence of stress that is caused by the dysfunctionalities of an online store [14, 15]. Literature refers to technology-induced stress as the phenomenon of technostress [14], leading to several negative influences on the consumer on a physical and psychological level as well as on behavioral responses that end-users display in the form of leaving \& future avoidance of the situation following a stressful experience $[16,17,18,19]$. While no further research has been conducted so far, those findings underpin the potential of technostress to also impede usual behavioral tendencies such as the preference for and purchase of sustainable products.

With the consumer's increased sustainability consciousness and the rise of e-commerce in the past years, a better understanding of the antecedents of and potential impediments to sustainable consumption becomes critical for online retailers to successfully compete in the market. Thus, we aim to extend the current research body by examining the role of technology-induced stress and its effects on the preference for sustainable products and the actual purchase decision in an experimental online shopping 
scenario. Additionally, we investigate how growth mindset indirectly affects consumers' sustainable purchase decisions, mediated by the preference for sustainable products.

The paper is structured as follows: Based on the theoretical foundations of implicit theories of personality traits and attributes, we explain the constructs of growth and fixed mindset and their relevance for sustainable consumer behavior, followed by the conceptualization of technostress. We deduce our research model and depict three hypotheses which we investigate in the experimental study design presented. After analyzing the results of our study, we conclude with the theoretical and practical contributions of our findings and draw implications for future research, based on the limitations of our study.

\section{Theoretical Foundation and Research Model}

\subsection{Mindset, Behavioral Inclination and Behaviors in the Context of Sustainable Consumption}

A mindset is defined by an individual's core assumptions, values and beliefs which influence how surrounding information is perceived and processed $[24,25,26]$. The concept of mindset is deeply rooted in the implicit theories of personality traits and attributes and is characterized by the way individuals understand themselves, others and the world around them, and based on that, react or behave in a certain way $[26,27]$. These implicit theories materialize in different conclusions on the malleability of certain conditions. While entity theories imply that attributes are rather fixed, invariant, or pre-defined, incremental theories are based on the idea that attributes can be influenced and thus develop and change over time [27]. Research on implicit theories has primarily attempted to reveal associations with learning behaviors, attitudes, and results, as well as psychological constructs such as resilience, well-being and general satisfaction with life $[27,28,29,30,31$, 32]. Results have shown that individuals believing their abilities can be influenced and developed over time, so-called incremental theorists, display higher levels of self-efficacy, internal locus of control and positive attitude for learning and personal development as well as they are more proactively searching for feedback than individuals with rather fixed beliefs on their abilities, who we refer to as entity theorists [29, 30]. Correspondingly, the general willingness of incremental theorists to train and develop has been observed to be higher which matches the observation that they show more efficient goal setting and monitoring behaviors and ultimately outperform entity theorists [28, 31, 33]. The observed discrepancies can be explained through the deviating beliefs, ideas and assumptions incremental and entity theorists apply and thus distinguished in two opposing mindsets: the growth mindset and the fixed mindset [26]. Incremental theorists applying a growth mindset evaluate success, failure, and effort differently, strive for continuous improvement, show a higher degree of motivation and willingness to perform as they believe their own abilities as well as the world around them to be malleable and dynamic. Entity theorists applying a fixed mindset assume their abilities and the characteristics of the world around them to be immutable and the ingrained determinants for success or failure [27, 34].

Examinations of implicit theories and the connected mindsets in the field of consumer behavior show that the differing perceptions of oneself and the willingness to make an effort impact purchase intentions and consumption behavior. Individuals applying a fixed mindset tend to prefer products that successfully satisfy their desire to confirm their subjective evaluation of current abilities and strengths with comparatively low effort. At the same time, individuals applying a growth mindset favor products subjectively associated with the opportunity to further improve their competencies and show a higher willingness to seek for and acquire products that have a potential positive influence on future selfdevelopment [35].

While the relevance of psychological factors as determinants supporting sustainable consumer intentions and behaviors, such as social and personal norms, emotions and beliefs, habit formation, selfefficacy, and perceived consumer effectiveness, has been broadly examined $[4,5,6,7,8,9,10]$, thus far research on how growth and fixed mindset as psychological factors may influence the intention for and realization of sustainable action is scarce. Building on the existing body of research, Soliman and Wilson (2017) were the first to introduce implicit theories as another psychological variable to reinforce engagement in the domain of sustainability and found a positive link between incremental theorists, applying a growth mindset and thinking of the world around them as changeable and dynamic, and the behavioral inclination towards future sustainable action, explained by their belief in the positive impact of their efforts. In turn, entity theorists, pursuing a fixed mindset, were less inclined to deem their individual efforts as an effective way to cause change and were less prone towards future sustainable action [11]. Duchi et al. (2020) build on and extend those findings 
by examining the impact of mindsets on actual behavior through assessing the self-reported frequency of sustainable actions. Their results provide support to the initial results of Soliman and Wilson (2017) by confirming the connection between application of growth mindset and the inclination towards future sustainable action as well as by further disclosing a positive relationship of a growth mindset with the increased frequency of actual engagement in sustainable actions [12].

\subsection{The Relevance of Technostress in the Context of E-Commerce}

While the overall perception of stress highly depends on both individual attributes as well as the characteristics of varying situations [36], Ragu-Nathan et al. (2008) refer to the stress particularly experienced when interacting with information and communication technologies (ICTs) as the phenomenon of technostress, namely that is stress "caused by an individual's attempts to deal with constantly evolving ICTs and the changing physical, social, and cognitive responses demanded by their use" [14, p. 418]. More specifically, it is defined as the outcome of simultaneous use of various applications or systems, being constantly connected and overloaded by continuous information flows, permanent updates of software and hardware as well as technical issues and disruptions [15], thus making technostress a multidimensional construct that is commonly categorized by different types of technostress creators, collectively explaining the occurrence of technostress $[14,15]$.

Research findings related to the occurrence of technostress and its effects on the consumer, have proven its relevance in the context of e-commerce and online shopping activities [14, 15]. It emerges that technostress can be triggered by constantly changing or counterintuitive user interfaces and the introduction of new or additional website functionalities [14, 37, 38]. Furthermore, the fear of fraud and data abuse when making a transaction as well as malfunctions of the website, e.g., system error notifications or breakdowns can lead to the experience of technostress $[16,39,40,41]$. Lastly, the occurrence of technostress is highly related to the overall information management of the used website and the required cognitive demand. In that regard, specifically information overload, opacity, irrelevance, or insufficiency have shown to be antecedents of technostress $[17,18,43]$.

On a broader scale, technostress combines all negative influences of human-computer-interaction on physiological and psychological factors [20, 21, 22,
23]. In addition, cognitive performance can diminish due to technostress leading to a lack of concentration, nervous breakdowns, and moral disengagement, caused by disruption or prevention of task completion [44, 45, 46, 47].

Studies, specifically focusing on the impact of technostress on the consumer in an e-commerce context, have reported results consistent with the overarching negative consequences of technostress on physical, psychological, and cognitive parameters [16, 19]. Another component - in the field of consumer research fundamentally important - is the behavioral consequence that consumers draw following technology-induced stress. The experience of technostress has shown to be associated with behavioral responses of flight and avoidance in the shape of shopping cart abandonment, purchase cancellation and the general rejection of e-services, turning to alternative providers, to mitigate and evade the stressful situation $[17,18,19]$.

\subsection{Research Model}

With the present study, we aim to connect existing research in the domains of sustainable consumption and technostress in an e-commerce context and gain insights into consumers' sustainable preference, and decision making. Our objective is to investigate the effects of technostress on the relationship between growth mindset and sustainable purchase decision and the effects' mediation through sustainable purchase preferences in the context of clothing goods, using an experimental study design. Based on the theoretical foundation presented above, we suggest a research model examining the effects of a growth mindset on sustainable product preferences and sustainable purchase decisions and their potential dilution through experienced technostress. We build on and extend the research of Soliman \& Wilson (2017) and Duchi et al. (2020) while acknowledging the existing research body on psychological variables influencing sustainable consumer intentions and behaviors.

Pursuing a growth mindset, thus being considered an incremental theorist, has been associated with sustainable behavioral inclinations very recently and only on a broader behavioral scheme so far [11]. In this context, the growth mindset was further introduced as an additional psychological variable that fosters overarching sustainability engagement. Generally, psychological factors have shown to be important determinants to sustainable consumer preference and intentions $[4,5,6,7,8,9,10]$. Thus, applying a certain mindset should influence the preference for sustainable products. More specifically, endorsing a growth mindset should positively impact the 
preference for sustainable products as, based on implicit theories, incremental theorists see the world as being malleable, dynamic and changeable and have trust in the positive impact of their actions [11]. In turn, pursuing a fixed mindset will not lead to increased preference for sustainable products, as entity theorists see the world as really fixed and if changeable at all, only very slowly and at no large scale, which in turn leads to them not believing in any further impact of their actions [11]. Therefore, we posit the following:

Hypothesis 1: Growth mindset has a positive impact on consumers' general preference for sustainable products.

Further research findings have disclosed a positive association not only between growth mindset and the inclination towards sustainable action, but also a subsequent positive effect on engagement in actual sustainable behaviors [12]. Based on the previous theoretical derivation, endorsing a certain mindset should indirectly impact the actual purchase of sustainable

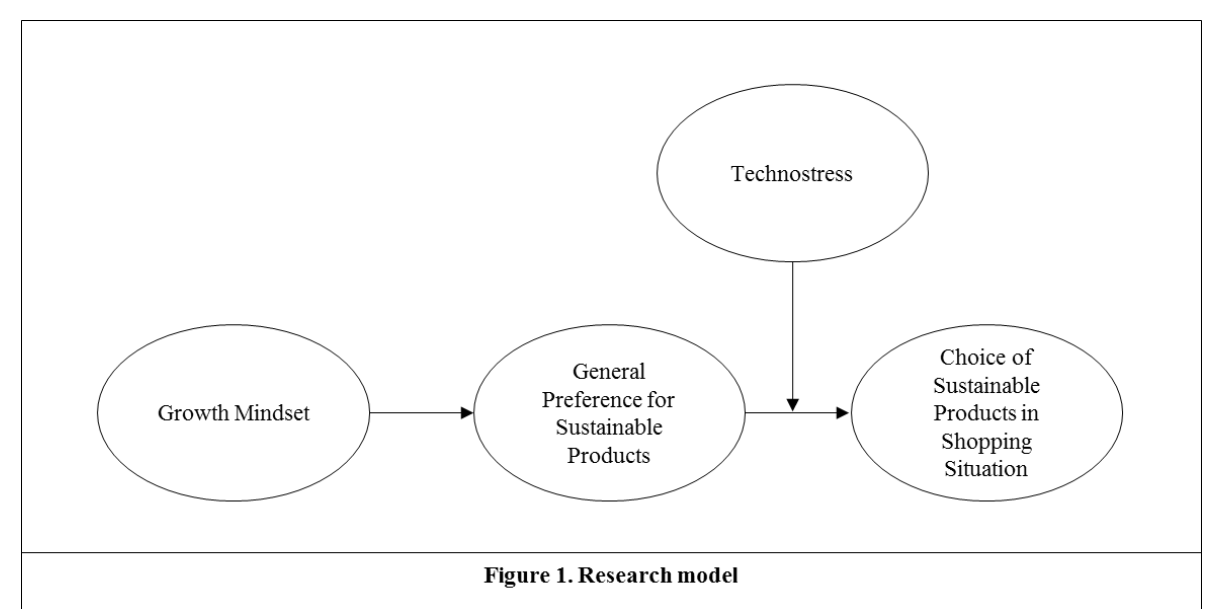
products through the mediation of preference for sustainable products. Thus, endorsing a growth mindset should not only positively impact the preference for sustainable products, but have an indirect effect on purchase decisions as well, mediated by the increased preference for sustainable products. The opposite should hold true when pursuing a fixed mindset. Accordingly, we propose the following:

Hypothesis 2a: Consumers' general preference for sustainable products has a positive effect on the choice of sustainable products in the online shopping situation.

Research has reported numerous influences of technostress on consumers' physical and mental wellbeing as well as their cognitive performance $[16,17$, $18,19,21]$. In particular, those negative effects created by the experience of technology-induced stress in an online shopping context have shown to lead to a change in behavioral responses of flight and avoidance under perceived stress compared to normal circumstances $[17,19,43,48,49]$. Connecting the existing research to the field of sustainable consumption, the negative impacts of technostress may trigger inconsiderate behaviors to quickly alleviate the situation by accepting and opting for purchase decisions contrary to regular sustainable product preferences. Our final hypothesis reflects this connection as follows:

Hypothesis 2b: The effect of consumers' general preference for sustainable products on their choice of sustainable products in the online shopping situation is moderated by the presence vs. absence of technostress.

Figure 1 depicts a graphical illustration of our research model.

\section{Empirical Study}

\subsection{Design and Participants}

To examine the effect of growth mindset on the choice of sustainable products in an online shopping situation through the mediator of participants' general preference for sustainable products depending on the level of technostress, we conducted an online survey with a between-participants experimental design (technostress manipulation vs. no technostress manipulation). The online study was shared by undergraduate and graduate students of a German university via link. Applying the data collection strategy of a snowball system, starting with students' acquaintances, friends and family members, we ensured a relatively heterogeneous age structure in relation to common age groups of online shoppers. We asked participants to put themselves in the situation that they are about to buy clothes in an online store called "Fashion for you".

121 people participated in the experiment. Approximately $56 \%$ of the sample is female. The mean age is 35.5 years $(\mathrm{SD}=14.5)$. The online questionnaire randomly exposed participants to the experimental vs. control condition, thus age and gender are equally 
distributed across both conditions (technostress manipulation vs. no technostress manipulation).

\subsection{Stimulus and Procedure}

Research on actual sustainable behaviors has so far lacked examination in an experimental setting and has only been assessed by self-report measures [12]. The present study draws on the depicted findings and aims to further extend existing research by utilizing an experimental study design. To investigate our research hypotheses, we created two fictional German online stores providing sustainable and non-sustainable clothing goods. To eliminate the effect of social desirability in the respondents' answering behavior, it was not explicitly communicated that the consumption of sustainable products was the focus of the experiment. The two stores discriminate based on technostress manipulation vs. no technostress manipulation and their overall layout was oriented towards the regular style of online stores.

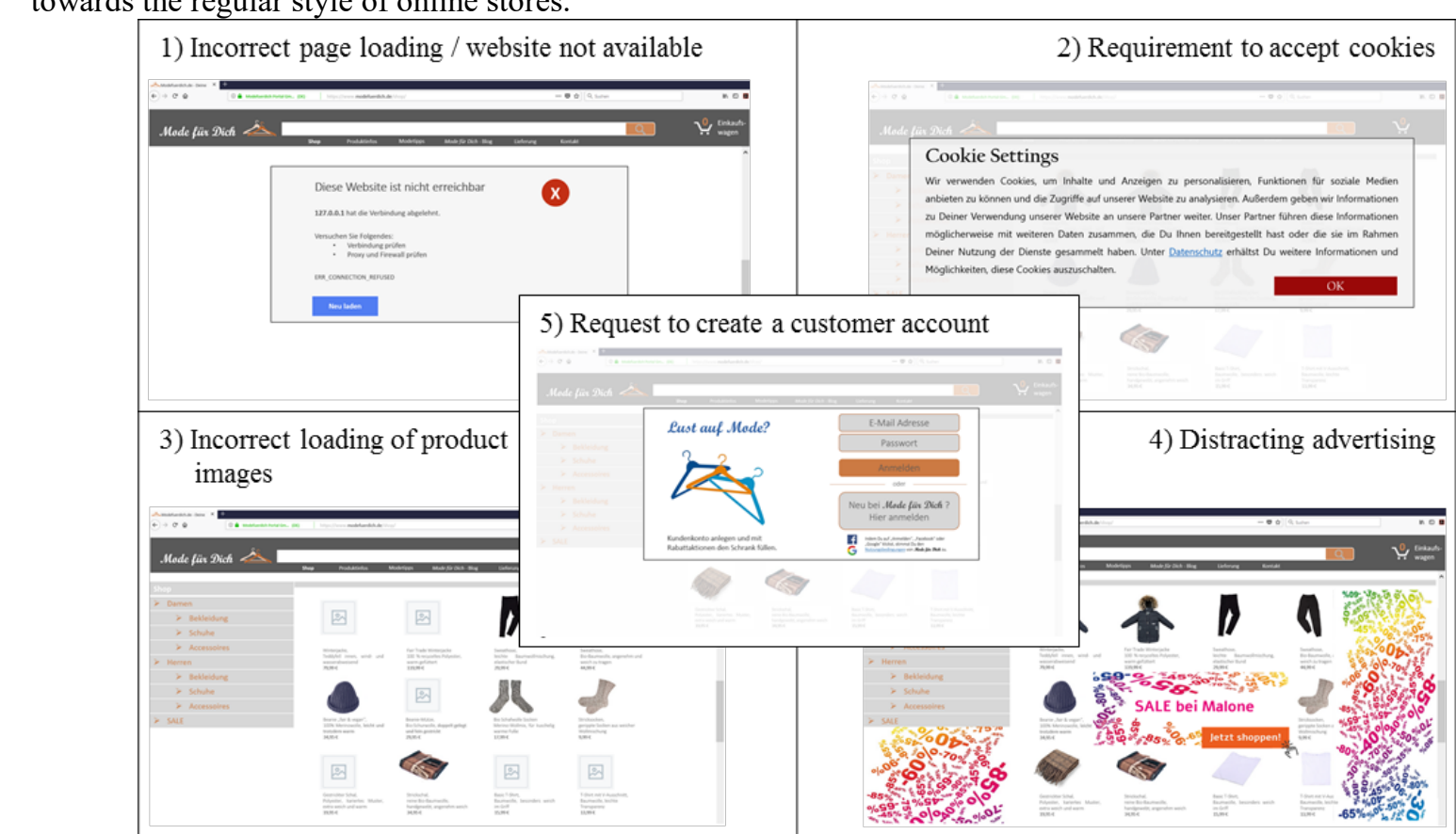

Figure 2. Technostress manipulation (experimental group) scenario. Figure 2 shows the technostress manipulation described.

After this technostress manipulation or a regular no technostress condition, respondents were asked to imagine that they were continuing their shopping and saw eight pairs of respectively two products, and were told to choose one of the two products of each pair by clicking on the respective product. To further reduce possible social desirability in respondents' answering behavior, the purpose of the study again was partially disguised in the product selection by embedding three distractor pairs consisting of either two sustainable products or two regular non-sustainable products in the product choices. Figure 3 gives an overview of product pairs and distractors.

\subsection{Construct Measures and Manipulation Checks}

The aspects of interest were measured relying
The manipulation of technostress was based on Tarafdar et al. 2019 [50], thus, including technical malfunctions in forms of an incorrect loading of website or product images, technical requirements such as the need to accept cookies or to create a customer account and advertising banners. Participants were randomly exposed to either a technostress manipulating or a no technostress upon scales developed and validated in multiple previous studies. We used eight items to capture respondents' growth mindset [51]. Respondents' general preference for sustainable products was measured with a two items scale evaluating participants' individual preference for ecological products or products produced and traded under fair conditions. To differentiate respondents' level of choice for sustainable products in the fictional online 
shopping situation, we created an index variable summing up all sustainable decisions taken, thus, leading to a minimum value of zero and a maximum value of five (no implementation of distractor product pairs).

We evaluated the measurement model for the construct of growth mindset by using a confirmatory factor analysis (CFA). In the course of CFA, the measurement of the complex constructs is formally represented by their indicators, with each individual indicator corresponding to a flawed measurement of the underlying construct [52]. Before conducting CFA, all negatively worded items were first recoded so that a high score on the scale also corresponds to a high correspondence on growth mindset construct. Local fit parameters applied show evidence of the validity and reliability of the construct measure. First, all factor loadings reach values of above 0.5 . Cronbach's alpha reached a value of 0.91 thus exceeding the commonly accepted threshold of 0.7 [53]. Average variance extracted (AVE) shows a value of 0.55 , thus exceeding the threshold of 0.50 . Composite reliability (CR) shows a value of 0.91 , thus exceeding the threshold of 0.60 [54]. As another local quality measure on indicator level, the t-value of the factor loadings is often considered to determine whether the factor loading of an indicator differs significantly from zero. In AMOS, instead of t-values, so-called critical ratios (C.R.), i.e., the ratio of estimated covariance and standard error, are output and can be used analogously for the quality assessment. All items exceeded the minimum threshold of C.R.-values larger than 1.96 [55].

With respect to manipulation checks, we performed a check for the manipulation of technostress on the online store website by asking participants to indicate the degree to which they perceived technostress in the respective website condition. Technostress perception of respondents was measured using three items which were designed and pretested to achieve appropriate construct reliability and validity. The wording of the items was as follows: 1) "The scenario shown puts me personally under stress", 2) "My stress level in such an online shopping situation is very high", 3) "I perceive the online shopping situations shown as very stressful". We used a seven-point Likert-type agreement scale ranging from 1 "Don't agree at all" to 7 "Fully agree". A two sample t-test indicated a significant difference $(\mathrm{t}(119)$ $\left.=8.33, \mathrm{p}<0.001 ; M_{\text {technostress }}=4.7, M_{\text {regular }}=2.5\right)$, thus pointing to a successful manipulation of technostress.

\subsection{Results}

We analyzed the data from the experimental study using regression analysis. Technically, our research model represents a moderated mediation model because we are interested in the effect of growth mindset on peoples' choice of sustainable products in an online shopping situation, mediated by their general preference for sustainable products and whether this causal chain is moderated by technostress. We used the macro PROCESS v3.5.3 for SPSS as provided by Hayes (2018) [56], which allows for comprehensive analysis of conditional process models. Prior to the regression analysis, we combined all multi-item constructs into average index variables.

We used Hayes' (2018) [56] model 14 for the

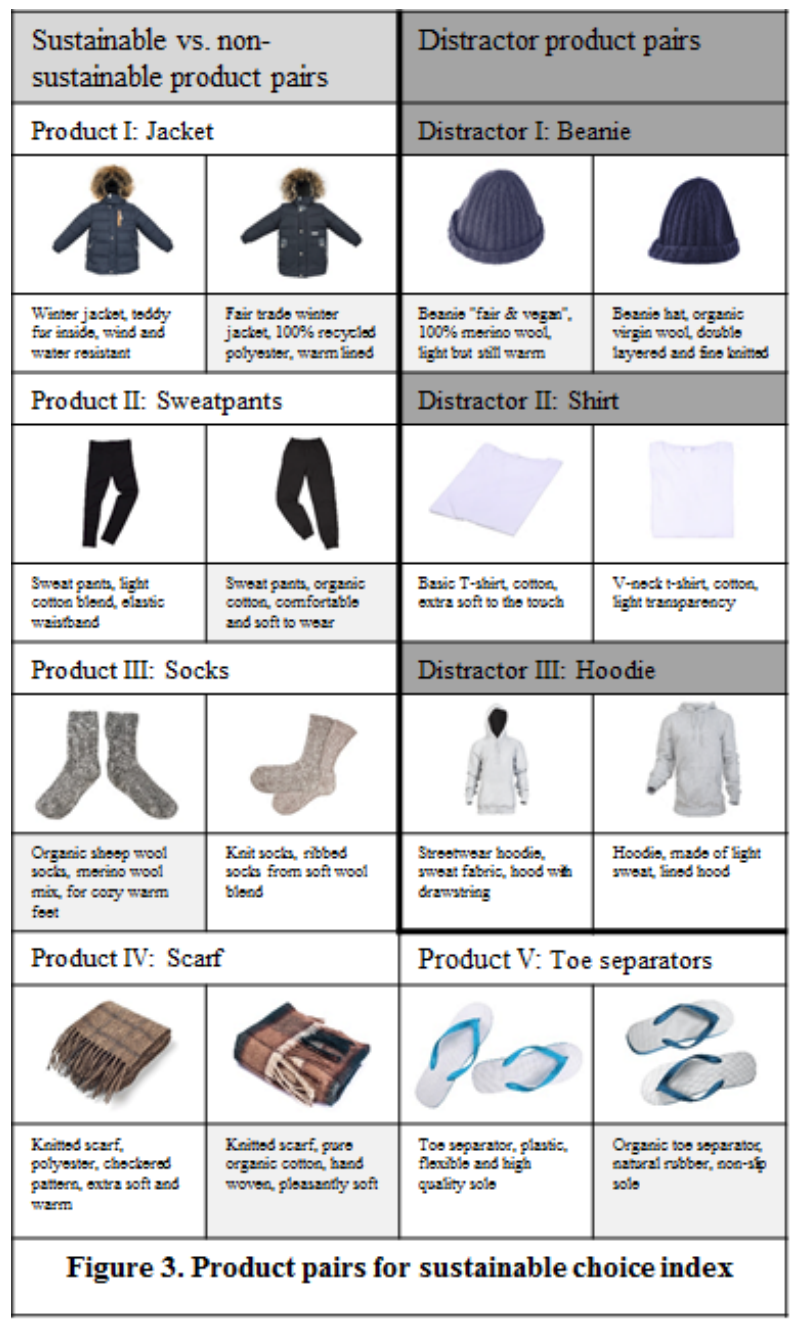

analysis. Technostress was entered as a binary moderator $(1=$ technostress condition). Furthermore, we entered respondents' general preference for sustainable products as mediator. Peoples' choice of sustainable products in the fictional online shopping 
scenario was the dependent variable of the analysis. In order to draw statistical inferences about the indirect effect of our model, we followed a bootstrapping approach [57], drew 5,000 bootstrap samples, and calculated $95 \%$ bias-corrected confidence intervals (CI).

Our first hypothesis predicts that people having a growth mindset show a higher general preference for sustainable products. Results from the regression analysis support this assumption, as we found a significant positive effect of growth mindset on general preference for sustainable products $(b=0.32$, $\mathrm{p}<0.01)$.

Our second hypothesis is twofold. First, we assume that consumers' general preference for sustainable products has a positive effect on their choice of sustainable products in the fictional online shopping situation. Results on this direct effect confirm our hypothesis, showing a highly significant positive effect of consumers' general preference for sustainable products on their choice of sustainable products in the fictional shopping context $(b=0.62, p$ $<0.001)$. Second, our hypothesis $2 \mathrm{~b}$ claims that the effect of consumers' general preference for sustainable products on their choice of sustainable products in the fictional online shopping situation is dependent on the perception of technostress. The results support this assumption, as we receive a significant interaction effect $(b=-0.37$; CI $[-0.66 ;-0.08]$.

Figure 4 shows a visualization of the moderating effect for both conditions of the experimental design of our study. Looking at the visualization of the

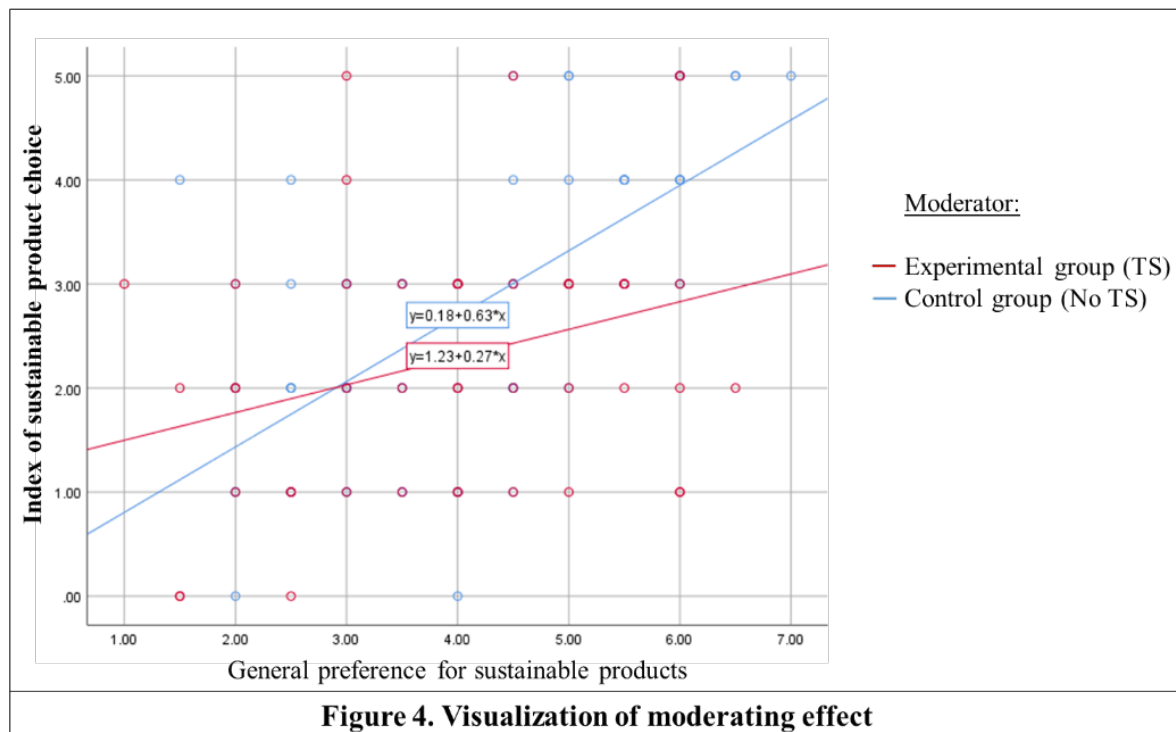

Figure 4. Visualization of moderating effect interaction term, it becomes apparent that the slope of the straight line for the control group (no technostress) is much steeper than the straight line for the experimental group (technostress). Accordingly, in the control group, a low general preference for sustainable products also leads to a reduced choice of sustainable products in the online shopping situation, whereas a high preference for sustainable products also manifests itself in an increased choice of sustainable products. However, this relationship is diminished in the experimental condition, i.e., the presence of technostress, resulting in a reduced choice of sustainable products despite a high preference for them (compared to the control group).

Finally, we hypothesize that a growth mindset influences the choice of sustainable products in an online shopping situation through general preference for sustainable products and that this effect is dependent on technostress. The results show that for both conditions of the technostress variable there is a significant indirect effect, drawing on 5,000 bootstrapping samples (technostress $=0: \mathrm{b}=0.62$, CI $[0.42 ; 0.81]$; technostress $=1: \mathrm{b}=0.24$, CI $[0.02$; $0.47]$ ) [58]. In line with this, we achieve a significant result for the index of moderated mediation $(\mathrm{i}=-0.18$; CI [-0.28; -0.01]).

Concluding our results, all hypotheses were confirmed.

\section{Discussion}

The findings of the present study underpin the relevance of technostress in the context of ecommerce. We provide new insights on how the perception of technology-induced stress diminishes sustainable consumption behaviors, despite preferences for sustainable products being associated with the pursuit of certain mindsets, deeply rooted in the implicit theories of personality traits and attributes. We contribute to the research fields of ICTs, ecommerce and consumer psychology by showing how external influences disrupt the purchase decision of consumers who are inclined towards purchasing sustainable products under non-invasive conditions.

First, our study reveals the threat of technostress in the context of online shopping and its detrimental power on the deeply rooted psychological concept of mindset through confirming the negative impact of 
technostress on consumers' sustainable purchase decision, despite preferring sustainable products under non-stressful conditions.

In line with previous research, we highlight the need for further research on technostress and its negative influence on psychological, emotional, and cognitive factors in the e-commerce domain [44], yet first practical implications can be drawn from the findings of the present study: Technical malfunctions and the complexity of online shops, as induced in our experimental manipulation, should be prevented and thoroughly taken care of by e-commerce operators. This includes securing server uptime, prevention of broken links, clean and well-placed advertisements, or the opportunity to purchase with one-time guest login instead of requiring a user account.

Moreover, we show that endorsing a growth mindset leads to higher general preference for sustainable products which in turn increases the actual choice of sustainable products. Our findings extend previous research on the effects of growth mindset and the general inclination towards and actual engagement in sustainable action by disclosing the same influence of growth mindset particularly on the preference for and purchase of sustainable products in an online shopping situation $[11,12]$. We provide first research evidence for the growth mindset being another psychological factor determining sustainable consumer intentions and behaviors. Gaining a holistic understanding of the antecedents supporting sustainable consumption is crucial to better tailor marketing and advertising activities to increase conversion rates on sustainable product offers [59].

Nevertheless, our study presents only the first step in examining the influence of growth mindset on sustainable consumption behaviors and therefore also faces certain limitations and need for further research. The research at hand focuses exclusively on the purchase of sustainable clothing goods, neglecting any other product category. To confirm the validity of growth mindset as a fundamental, distinct psychological factor towards sustainable consumer intentions and behaviors, the results of the present study should be replicated in product categories, such as food, cosmetics or hygiene products. Furthermore, the experimental setting of our study did not consider the individual differences in coping with technostress in an online store. However, since the pursuit of a growth mindset is associated with the application of proactive coping strategies, future research should investigate if this holds true when consumers, endorsing a growth mindset, experience technologyinduced stress while shopping online $[60,61]$.

Lastly, future research should focus on the opportunities to push sustainable behaviors in an online shopping context. In consumer psychology and marketing, nudging is a well-known technique to steer consumers' choices in a certain direction [62]. The knowledge about the behavioral tendencies both growth and fixed mindset entail could be used to design online shops in a way that triggers sustainable consumption behaviors. This way, even consumers pursuing a fixed mindset, therefore being less inclined towards sustainable product preferences and purchasing behaviors, may be driven towards prosustainable purchase decisions, for example when the effort to purchase the sustainable product is equal to a non-sustainable alternative or the advertisement of the sustainable option is explicitly tailored towards the consumers' desire to confirm the positive appraisal of their current self instead of focusing the marketing on the positive future impact of sustainable action [35].

\section{References}

[1] Business and Sustainable Development Commission, Better Business, Better World Report, Better Business, Better World (UN.org), 2017, link retrieved on: June, 11 th 2021.

[2] McKinsey and Company, The State of Fashion Report, The State of Fashion 2020 (mckinsey.com), 2020, link retrieved on June, 11th 2021.

[3] Auger, P., and T. M. Devinney, "Do What Consumers Say Matter? The Misalignment of Preferences with Unconstrained Ethical Intentions", Journal of Business Ethics, 76(4), 2007, pp. 361-383.

[4] Lin, S.-T., and H.-J. Niu, "Green Consumption: Environmental Knowledge, Environmental Consciousness, Social Norms, And Purchasing Behavior", Business Strategy and the Environment, 27(8), 2008, pp. 1679-1688.

[5] Jansson, J., A. Nordlund, and K. Westin, "Examining Drivers of Sustainable Consumption: The Influence of Norms and Opinion Leadership on Electric Vehicle Adoption in Sweden", Journal of Cleaner Production, 154, 2017, pp. 176-187.

[6] Singh, J. J., N. Garg, R. Govind, and S. J. Vitell, "Anger Strays, Fear Refrains: The Differential Effect of Negative Emotions on Consumers' Ethical Judgments", Journal of Business Ethics, 151(1), 2018, pp. 235-248.

[7] Antonetti, P., and S. Maklan, "Feelings that Make a Difference: How Guilt and Pride Convince Consumers of the Effectiveness of Sustainable Consumption Choices", Journal of Business Ethics, 124(1), 2014, pp. 117-134.

[8] Welsch, H., and J. Kuehling Kuehling, "Determinants of pro-environmental consumption: The role of reference groups and routine behavior", Ecological Economics, 69(1), 2009, pp. 166-176.

[9] Lin, H.-Y., and M.-H. Hsu, "Using Social Cognitive Theory to Investigate Green Consumer Behavior", Business Strategy and the Environment, 24(5), 2015, pp. 326-343. 
[10] Yarimoglu, E., and G. Binboga, "Understanding sustainable consumption in an emerging country: The antecedents and consequences of the ecologically conscious consumer behavior model", Business Strategy and the Environment, 28(4), 2019, pp. 642651.

[11] Soliman, M., and A.E. Wilson, "Seeing change and being change in the world: The relationship between lay theories about the world and environmental intentions", Journal of Environmental Psychology, 50, 2017, pp. 104-111.

[12] Duchi, L., D. Lombardi, F. Paas, and S. Loyens, "How a Growth Mindset Can Change the Climate: The Power of Implicit Beliefs in Influencing People's View and Action”, Journal of Environmental Psychology, 70, 2020, pp. 101461.

[13] Netcomm Suisse Observatory and United Nations Conference on Trade and Development, "Covid-19 and E-commerce: Findings from a survey of online consumers in 9 countries", (dtlstictinf2020d1_en.pdf (unctad.org)), 2020, link retrieved on: June, 11th 2021.

[14] Ragu-Nathan, T. S., M. Tarafdar, B. S. Ragu-Nathan, and Q. Tu, "The Consequences of Technostress for End Users in Organizations: Conceptual Development and Empirical Validation", Information Systems Research, 19(4), 2008, pp. 417-433.

[15] Tarafdar, M., Q. Tu, and T. S. Ragu-Nathan, "Impact of Technostress on End-User Satisfaction and Performance", Journal of Management Information Systems, 27(3), 2011, pp. 303-334.

[16] Riedl, R., H. Kindermann, A. Auinger, and A. Javor, „Technostress from a Neurobiological Perspective: System Breakdown Increases the Stress Hormone Cortisol in Computer Users", Business \& Information Systems Engineering, 4(2), 2012, pp. 6169.

[17] Fuentes, C., and A. Svingstedt, "Mobile shopping and the practice of shopping: A study of how young adults use smartphones to shop", Journal of Retailing and Consumer Services, (38), 2017, pp. 137-146.

[18] Persad, K., and K. Padayachee, "The factors that influence customer e-services adoption", South African Computer Journal, 56(1), 2015, pp. 80-106.

[19] Moody, G. D., and D. F. Galletta, "Lost in Cyberspace: The Impact of Information Scent and Time Constraints on Stress, Performance, and Attitudes Online", Journal of Management Information Systems, 32(1), 2015, pp. 192-224.

[20] Salanova, M., S. Llorens, and E. Cifre, "The Dark Side of Technologies: Technostress among Users of Information and Communication Technologies", International Journal of Psychology, 48(3), 2013, pp. 422-436.

[21] Riedl, R., "On the Biology of Technostress: Literature Review \& Research Agenda", The DATA BASE for Advances in Information Systems, 44(1), 2013, pp. 1855.

[22] Thomée, S., M. Ekloef, E. Gustafsson, R. I. Nilsson, and M. Hagberg, "Prevalence of Perceived Stress, Symptoms of Depression and Sleep Disturbances in Relation to Information and Communication
Technology (ICT) Use Among Young Adults - an Explorative Prospective Study", Computers in Human Behavior, 23(3), 2007, pp. 1300-1321.

[23] Reinecke, L., S. Aufenanger, M.E. Beutel, M. Dreier, O. Quiring, B. Stark, K. Wölfling, and K. W. Müller, „Digital Stress over the Life Span: The Effects of Communication Load and Internet Multitasking on Perceived Stress and Psychological Health Impairments in a German Probability Sample", Media Psychology, 2016, pp. 1-26.

[24] Paul, H., "Creating a mindset", Thunderbird International Business Review, 42(2), 2000, pp. 187200.

[25] Fang, F., S.-P. Kang, and S. Liu, "Measuring mindset change in the systemic transformation of education", Association for Educational Communications and Technology, 27th, Chicago, IL, 2004.

[26] Dweck, C. S., Mindset: The New Psychology of Success, Random House, New York, USA, 2006.

[27] Dweck, C. S., C.-Y. Chiu, and Y.-Y. Hong, "Implicit Theories and Their Role in Judgments and Reactions: A World From Two Perspectives", Psychological Inquiry, 6, 1995, pp. 267-285.

[28] Van Vianen, A. E. M., B. A. G. Dalhoeven, and A. E. De Pater, "Aging and Training and Development Willingness: Employee and Supervisor Mindsets", Journal of Organizational Behavior, 32, 2011, pp. 226247.

[29] Dweck, C. S., and E. L. Leggett, "A Social-Cognitive Approach to Motivation and Personality", Motivation and Personality, 95(2), 1988, pp. 256-273.

[30] Maurer, T. J., K. A. Wrenn, H. A. Pierce, S. A. Tross, and W. C. Collins, "Beliefs About 'Improvability' of Career-Relevant Skills: Relevance to Job/Task Analysis, Competency Modelling, and Learning Orientation", Journal of Organizational Behavior, 24(1), 2003, pp. 107-131.

[31] Blackwell, L., K. H. Trzesniewski, and C. S. Dweck, "Implicit Theories of Intelligence Predict Achievement Across an Adolescent Transition: A Longitudinal Study and an Intervention", Child Development, 78(1), 2007, pp. 246-263.

[32] King, R. B., "A Fixed Mindset Leads to Negative Affect: The Relations Between Implicit Theories of Intelligence and Subjective Well-Being", Zeitschrift für Psychologie, 225(2), 2017, pp. 137-145.

[33] Burnette, J. L., E. H. O’Boyle, E. M. VanEpps, J. M. Pollack, and E. J. Finkel, E. J., "Mind-Sets Matter: A Meta-Analytic Review of Implicit Theories and SelfRegulation”, Psychological Bulletin, 139(3), 2013, pp. 655-701.

[34] Dweck, C. S., and J. Neubauer, Selbstbild: wie unser Denken Erfolge oder Niederlagen bewirkt, Campus Verlag, Frankfurt/Main, Germany, 2007.

[35] Murphy, M. C., and C. S. Dweck, "Mindsets shape consumer behavior", Journal of Consumer Psychology, 26(1), 2016, pp. 127-136.

[36] Lazarus, R. S., Psychological stress and the coping process, McGraw-Hill, New York, USA, 1966.

[37] Green, D, T., and J. M. Pearson, "Integrating website usability with the electronic commerce acceptance 
model", Behaviour \& Information Technology, 30(2), 2011, pp. 181-199.

[38] Tung, L. L., Y. Xu, and F. B. Tan, “Attributes of Web Site Usability: A Study of Web Users with the Repertory Grid Technique", International Journal of Electronic Commerce (13:4), 2009, pp. 97-126.

[39] Fuentes-Blasco, M., I.-G. Saura, G. Berenguer-Contrí, and B. Moliner-Velázquez, B., "Measuring the antecedents of e-loyalty and the effect of switching costs on website", Service Industries Journal, 30(11), 2010, pp. 1837-1852.

[40] Glover, S., and I. Benbasat, "A Comprehensive Model of Perceived Risk of E-Commerce Transactions," International Journal of Electronic Commerce, 15(2), 2010, pp. 47-78.

[41] Hartono, E., C. W. Holsapple, K.-Y. Kim, K.-S. Na, and J. T. Simpson, "Measuring perceived security in B2C electronic commerce website usage: A respecification and validation", Decision Support Systems, 62, 2014, pp. 11-21.

[42] Zhu, L., I. Benbasat, and Z. Jiang, "Let's Shop Online Together: An Empirical Investigation of Collaborative Online Shopping Support", Information Systems Research, 21(4), 2010, pp. 872-891.

[43] Zhou, L., W. Wang, J. Xu, T. Liu, and J. Gu, "Perceived information transparency in B2C e-commerce: An empirical investigation", Information \& Management, 55(7), 2018, pp. 912-927.

[44] Tarafdar, M., C. L. Cooper, and J. F. Stich, "The Technostress Trifecta: Techno Eustress, Techno Distress and Design: Theoretical Directions and an Agenda for Research", Information Systems Journal, 29(1), 2019, pp. 6-42.

[45] Fischer, T., and R. Riedl, "Technostress Research: A Nurturing Ground for Measurement Pluralism?", Communications of the Association for Information Systems, 40(1), 2017, pp. 375-401.

[46] Salo, M., H. Pirkkalainen, C. E. H. Chua, and T. Koskelainen, "Formation and Mitigation of Technostress in the Personal Use of IT", MIS Quarterly, 46/Forthcoming 2022.

[47] D’Arcy, J., T. Herath, and M. Shoss, “Understanding Employee Responses to Stressful Information Security Requirements: A Coping Perspective", Journal of Management Information Systems, 31(2), 2014, pp. 285-318.

[48] Starcke, K., C. Polzer, O. T. Wolf, and M. Brand, "Does stress alter everyday moral decision- making?", Psychoneuroendocrinology, 36(2), 2011, pp. 210-219.

[49] Dedovic, K., C. D'Aguiar, and J. C. Pruessner, "What stress does to your brain: a review of neuroimaging studies", Canadian journal of psychiatry, 54(1), 2009, pp. 6-15.

[50] Tarafdar, M., C. Maier, S. Laumer, and T. Weitzel, "Explaining the link between technostress and technology addiction for social networking sites: A study of distraction as a coping behavior", Information Systems Journal, 30(1), 2020, pp. 06-124.

[51] Dweck, C. S., Self-theories: Their role in motivation, personality and development, Taylor \& Francis, Philadelphia, USA, 2000.
[52] Homburg, C., and A. Giering, "Konzeptualisierung und Operationalisierung komplexer Konstrukte - Ein Leitfaden für die Marketingforschung", Marketing Zeitschrift für Forschung und Praxis, 18(1), 1996, pp. 5-24.

[53] Nunnally, J., Psychometric Methods, McGraw-Hill, New York, USA, 1978.

[54] Bagozzi, R. P., and Y. Yi, "On the evaluation of structural equation models", Journal of the Academy of Marketing Science, 16(1), 1988, pp. 74-94.

[55] Backhaus, K., B. Erichson, and R. Weiber, Fortgeschrittene Multivariate Analysemethoden, Eine anwendungsorientierte Einführung, Springer Gabler, 3rd edition, Berlin, Germany, 2015.

[56] Hayes, A. F., Introduction to mediation, moderation, and conditional process analysis: A regression-based approach, 2nd edition, Guilford press, New York, USA, 2018.

[57] Preacher, K. J., and A. F. Hayes, "Asymptotic and resampling strategies for assessing and comparing indirect effects in multiple mediator models", Behavior Research Methods, 40(3), 2008, pp. 879-891.

[58] Hayes, A. F., "An index and test of linear moderated mediation", Multivariate Behavioral Research, 50(1), 2015, pp. 1-22.

[59] Kotahwala, K., "The psychology of sustainable consumption", Progress in Brain Research, 253, 2020, pp. 283-308.

[60] Burnette, J. L., L. E. Knouse, D. T. Vavra, E. O’Boyle, and M. A. Brooks, "Growth mindsets and psychological distress: A meta-analysis", Clinical Psychology Review, 77(1), 2020, 101816.

[61] Jamieson, J. P., A. J. Crum, J. P. Goyer, M. E. Marotta \& M. Akinola, "Optimizing stress responses with reappraisal and mindset interventions: an integrated model", Anxiety, Stress, \& Coping, 31(3), 2018, 245261.

[62] Thaler, R. H., and C. R. Sunstein, Nudge: Improving Decisions about Health, Wealth, and Happiness, Yale University Press, New Haven, USA, 2008. 